\title{
The Design of Driving Throttle Machine Legs System Based on Ziegler Nichols PID Control
}

\author{
Renli WANG ${ }^{1, a}$, Yueming DAl ${ }^{2, b}$ \\ ${ }^{1}$ Department of Information and Electric Engineering, Xuzhou Institute of Technology, Xuzhou, \\ 221111, China \\ ${ }^{2}$ Department of Information and Electric Engineering, Xuzhou Institute of Technology, Xuzhou, \\ 221111, China \\ aemail: renliwang@163.com, bemail: daiym63@163.com
}

Keywords: Adaptive PID control; Ziegler and Nichols parameter setting; Throttle mechanical leg; Critical stable

\begin{abstract}
Auto throttle controls directly the speed of the car. The driver can trample accurately and smoothly trample accelerator pedal to control the speed. In order to make the driver can real-time track the set the speed in the process of vehicle driving, a method based on Ziegler Nicholsfrequency response of the adaptive PID controller is proposed. The control circuit identifies online important critical frequency response characteristics of process object through input and output data in the process normal operation, and then the system online update PID controller parameters based on Ziegler-Nichols setting rules or by the improved method. The method can smoothly, rapidly and accurately control the throttle mechanical leg, and make driving robots has good speed tracking precision during the automatic driving of vehicle. The method has good stability and robustness.
\end{abstract}

\section{The Mathematical Model of the Throttle Mechanical Legs System}

Assume that ac motor: rated voltage $\mathrm{U}_{0}=36 \mathrm{~V}$, rated current $\mathrm{I}_{0}=6.7 \mathrm{~A}$, rated power $\mathrm{P}_{0}=180 \mathrm{~W}$, rated speed $\mathrm{N}_{0}=3000 \mathrm{r} / \mathrm{min}$, torque constant $\mathrm{Km}=0.085 \mathrm{~N} \bullet \mathrm{m} / \mathrm{A}$, rotor inertia $\mathrm{J}_{0}=2.3^{*} 10^{-5} \mathrm{Kg} \cdot \mathrm{m}^{2}$, motor magnetic logarithmic $\mathrm{P}=2$, motor viscous friction coefficient $\mathrm{f}_{0}=1.8^{*} 10^{-3} \mathrm{~N} \cdot \mathrm{m} \cdot \mathrm{S}$, resistance $\mathrm{R}=0.9 \Omega$, inductance $\mathrm{L}=2 * 10^{-3} \mathrm{H}$, potential constant $\mathrm{Ke}=8.9 \mathrm{~V} / \mathrm{Kr}^{\bullet} \mathrm{m}^{-1}$, rated torque $\mathrm{T}_{0}=0.57 \mathrm{~N} \bullet \mathrm{m}$, reducer reduction ration $=20: 1$, Load is equivalent to the viscous friction coefficient of the motor shaft $\mathrm{f}_{1}=2.5^{*} 10^{-3} \mathrm{~N} \cdot \mathrm{m} \cdot \mathrm{S}$, moment of inertia $\mathrm{J}_{1}=0.1 \mathrm{Kg} \cdot \mathrm{m}^{2}$.

Then $\mathrm{J}=\mathrm{J}_{0}+\eta^{-2} \mathrm{~J}_{1}=2.73 * 10^{-4} \mathrm{Kg} \cdot \mathrm{m}^{2}, \mathrm{~F}=\mathrm{f}_{0}+\eta^{-2} \mathrm{f}_{1}=1.81 * 10^{-3} \mathrm{~N} \cdot \mathrm{m} \cdot \mathrm{S}$, The transfer function is [1] [2]:

$$
G(s)=\frac{K m}{\eta S[(L S+R)(J S+F)+K e K m]}=\frac{42500}{5.46 S^{3}+2943 S^{2}+23900 S}
$$

Join the input and output speed conversion link, to meet the system requirements.

\section{The PID Controller Parameters Influence on Control Performance}

$$
\begin{aligned}
& \Delta u(k)=u(k)-u(k-1)=K_{P}[e(k)-e(k-1)]+K_{I} e(k)+K_{D}[e(k)-2 e(k-1)+e(k-2)] \\
& u(k)=K_{P}\left\{e(k)+\frac{T}{T_{I}} \sum_{j=0}^{k} e(j)+\frac{T_{D}}{T}[e(k)-e(k-1)]\right\}
\end{aligned}
$$

Formula (2) is called incremental PID control formula; Formula (3) is called position type PID control equation [3]. 
In the type: Kp is proportional coefficient, $K_{I}=K_{P} \frac{T}{T_{I}}$ is integral coefficient and $K_{D}=K_{P} \frac{T_{D}}{T}$ is differential coefficient.

\section{Ziegler Nichole to Realize the PID Parameter Setting}

Ziegler and Nichols method has developed online parameters setting between experience and calculation method. Ziegler Nichols method may determine very precise parameters for controller, it also can fine-tune after this [4] [5].

\subsection{Ziegler Nichols PID Parameter Setting Method}

(1) Build a closed loop control circuit, determine the stability limit.

(2) According to the formula to calculate the controller parameters.

The stability limit is determined by the P component. When there is a steady oscillation to reach this limit, the critical coefficient Kpcrit and critical oscillation cycle Tcrit are generated. After determining the critical coefficient Kpcrit and critical oscillation period Tcrit, we calculate other parameters according to a formula in the table below.

Specific as follows:

(1) Make Ki and Kd set 0, Kp set a smaller value, make the system into stable operation;

(2) Gradually increase the proportion coefficient $\mathrm{Kp}$, until the system generates stable and continuous oscillation, record the critical coefficient Kpcrit and the critical oscillation cycle Tcrit of this time;

(3) According to the experience formula of Table 1 and the corresponding controller type set corresponding PID parameters, and then conduct simulation validation and fine-tuning:

Table 1 PID parameters calculating formula

\begin{tabular}{|c|c|c|c|c|c|}
\hline \multirow{2}{*}{$\begin{array}{c}\text { The } \\
\text { controll } \\
\text { er type }\end{array}$} & \multicolumn{5}{|c|}{ characteristic data } \\
\cline { 2 - 6 } & $K_{P}$ & $T_{I}$ & $T_{D}$ & $K_{i}$ & $K_{D}$ \\
\hline & 0.6 & 0.5 & 0.12 & & \\
PID & $K_{\text {Pcrit }}$ & $T_{\text {crit }}$ & $T_{\text {crit }}$ & $\frac{K_{P}}{T_{I}}$ & $K_{P} T_{D}$ \\
\hline
\end{tabular}

For the transfer function of a given controlled object, we select the intersection point between root locus diagram of discrete system and z plane unit circle on the root locus diagram, then we gain $\mathrm{Km}$ and this point value namely . Setting formula is as follows:

$K_{p}=0.6 K_{m}$

$K_{d}=\frac{K_{P} \pi}{4 \omega_{m}}$

$K_{i}=\frac{K_{P} \omega_{m}}{\pi}$

In formula , $\mathrm{Km}$ is the $\mathrm{Kp}$ values of the system initiate oscillation, $\omega_{m}$ for the oscillation frequency. Oscillation frequency $\omega_{m}$ can be determined by the pole Angle $\theta$ located on the unit circle, $\omega_{m}=\theta / \mathrm{T}$ ( $\mathrm{T}$ for the sampling period). 


\subsection{The Matlab Setting Program}

Take sampling period: $\mathrm{T}=0.25 \mathrm{~s}$. The amplifier amplification coefficient $\mathrm{K}=50$. The operation result is shown in Fig. 1.

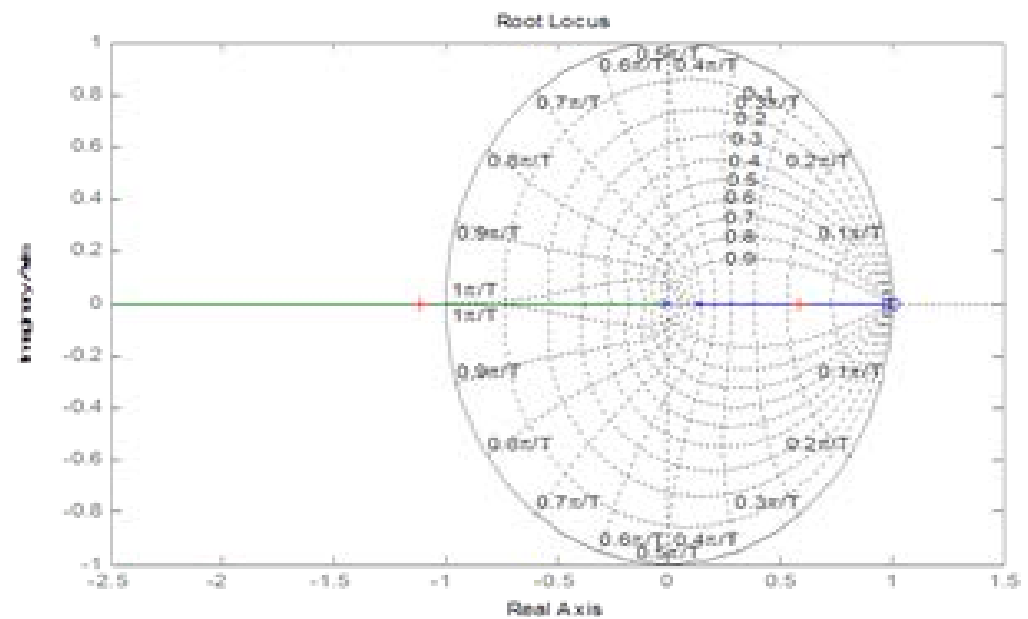

Fig. 1 As Root Locus Diagram Of Program Is Running Select a point in the graphics window.

Selected $\mathrm{kp}=0.2068 ; \mathrm{kd}=0.0129 ; \mathrm{ki}=0.821$.

\section{Simulink Simulation}

\subsection{To Construct a System of Simulink Model}

A method based on Ziegler Nichols- frequency response of the adaptive PID controller is proposed, aim function is found, design variables and the corresponding optimization algorithm to optimize a complete set of institutions are selected[6] [7]. System simulation model is shown in Fig. 2. Through the test the final performance parameters of the institution are obtained. Experiments show that the system has higher accuracy and stability, and can real-time track the set the speed in the process of vehicle driving, and achieved good ideal control effect. System simulation model

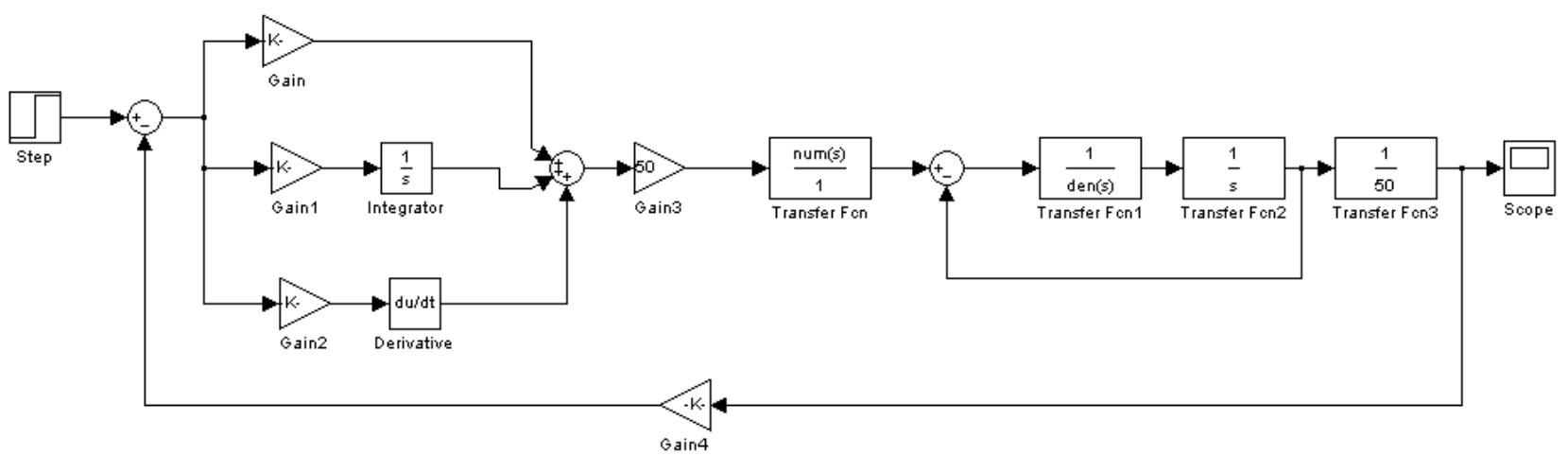

Fig. 2 Diagram of Simulink Model

\subsection{The Results of Simulation}

The experimental results are shown in Fig.3. The results show that the system has a good response speed, stability and accuracy, and strong robustness. 


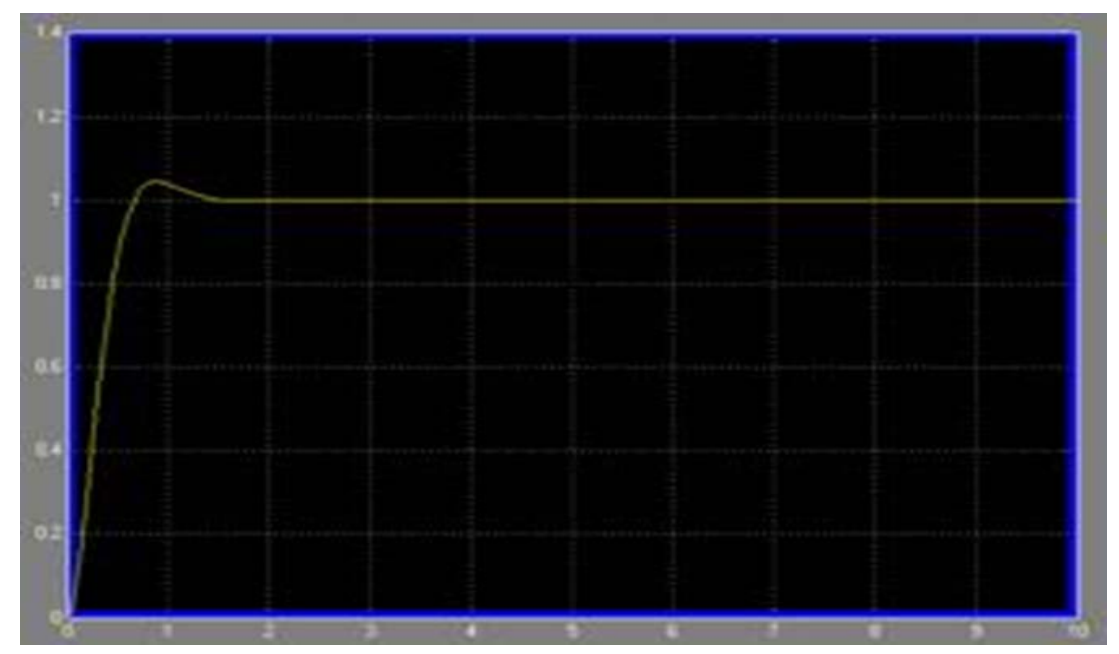

Fig.3 the Experimental Results

\section{Conclusions}

In a closed loop control system, the integral control link improves the steady-state error accuracy of the system. Due to the constantly accumulated error, it can eliminate the error quickly, but it make the system produces overshoot; And differential control can increase the damping of the system, improve the dynamic response speed. Because the PID controller can compensate the vast majority of the control system, the setting method is simple and good robustness; therefore it is currently the most widely used controller. Ziegler - Nichols methods are method of PID setting based on system stability analysis. Ziegler - Nichols method can quickly and accurately calculate the corresponding parameter numerical, then only need to fine-tune the ideal control effect can be got.

The simulation results show that the system response speed Is quick, the overshoot is small, the system stability is strong. By constantly adjust $\mathrm{Kp} 、 \mathrm{Ki} 、 \mathrm{Kd}$ in real time, the system can realize the good tracking of signal.

This method can realize the PID controller adaptive and ensure the control loop always work in the best condition even under the operating conditions change. It is of great significance for industrial enterprises the energy-saving emission reduction and improving the operation efficiency of process equipment.

\section{Preferences}

[1] Tang Jie, Motor and Drag (second edition) [M], higher education press, 2007.

[2]Gu Deying, Computer Control technology (3rd edition) [M], Beijing university of posts and telecommunications, 2012.

[3]Chen Boshi, Electric Drive Automatic Control System [M], mechanical industry publishing house,2011.

[4]MirSaleh Bahavarnia, Mohammad Saleh Tavazoei, A new view to Ziegler-Nichols step response tuning method: Analytic non-fragility justification[J], Journal of Process Control, 2013:23(1), 23-33.

[5]Tomislav B. Šekara, Miroslav R. Mataušek, Revisiting the Ziegler-Nichols process dynamics characterization, [J] Journal of Process Control, 2010:20(3), 360-363.

[6]Zhao Jingbo, MATLAB Simulation and Control System Design[M], mechanical industry publishing house, 2010.

[7]Liu Jinkun, Advanced PID Control MATLAB Simulation[M], the electronic industry press,2011. 
